\title{
Investigating the effect of previous treatments on wheat biomass over multiple spatial frequencies
}

\author{
A. E. Milne ${ }^{1}$, M. T. Castellanos ${ }^{2}$, M. C. Cartagena ${ }^{3}$, A. M. Tarquis ${ }^{4}$, and R. M. Lark ${ }^{1}$ \\ ${ }^{1}$ Rothamsted Research, Harpenden, Hertfordshire AL5 2JQ, UK \\ ${ }^{2}$ Centro Agraria El Chaparrillo - Delegación Provincial de Agricultura, c. Alarcos 21, Ciudad Real, 13071, Spain \\ ${ }^{3}$ Dpto. Química y Análisis Agrícola, E.T.S.I.A., Universidad Politecnica de Madrid, Spain \\ ${ }^{4}$ CEIGRAM, E.T.S.I.A., Universidad Politecnica de Madrid, Ciudad Universitaria sn, Madrid, 28040, Spain
}

Received: 21 December 2009 - Published in Biogeosciences Discuss.: 25 March 2010

Revised: 18 August 2010 - Accepted: 3 September 2010 - Published: 16 September 2010

\begin{abstract}
In this study we use the maximum overlap discrete packet transform (MODWPT) to investigate residual effects on wheat biomass of fertigation treatments applied to a previous crop. The wheat crop covered nine subplots from a previous experiment on melon response to fertigation. Each subplot had previously received a different level of applied nitrogen. Many factors affect wheat biomass, causing it to vary at different spatial frequencies. We hypothesize that these will include residual effects from fertilizer application (at relatively low spatial frequencies) and the local influence of individual plants from the previous melon crop (at high frequency). To test this hypothesis we use the MODWPT to identify the dominant spatial frequencies of wheat biomass variation, and analyse the relationship to both the previous fertilizer application and the location of individual melon plants in the previous crop. The MODWPT is particularly appropriate for this because it allows us first to identify the key spatial frequencies in the wheat biomass objectively and to analyse them, and their relationship to hypothesized driving factors without any assumptions of uniformity (stationarity) of wheat-biomass variation.

The results showed that the applied nitrogen dominated the wheat biomass response, and that there was a noticeable component of wheat-biomass variation at the spatial frequency that corresponds to the melon cropping. We expected wheat biomass to be negatively correlated with the position of melons in the previous crop, due to uptake of the applied nitrogen. The MODWPT, which allows us to detect changes in correlation between variables at different frequencies, showed that such a relationship was found across part of the experiment but not uniformly.
\end{abstract}

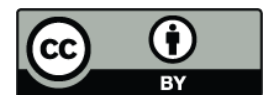

Correspondence to: A. E. Milne (alice.milne@bbsrc.ac.uk)

\section{Introduction}

Soil properties are the result of spatially variable factors operating over multiple orders of spatial frequency (here after "frequency"). We have some knowledge of the size and variability of many factors that influence variability either because they result from human actions, such as fertilizer application, or because we have made measurements that characterize them. If we evaluate the variation (and correlation) of these variables at different frequencies, we are often able to understand how the dominant factors that influence the property of interest change with frequency, and quantify their relative importance. In this paper we investigate how wheatbiomass data reflect known past treatments. We need to understand the carry-over effects of previous treatments if we are to manage nutrients in a spatially variable way (Bausch, 2005) so as to account for previous applications when planning those for the current season. Here we show how an analysis of biomass variation by spatial frequency can help us to characterise such effects.

Residual effects of nitrogen have been investigated by other workers (McCracken et al., 1989; Ruffo et al., 2004; Karlen et al., 1998), in studies generally focused on management of excess $\mathrm{NO}_{3}-\mathrm{N}$ to reduce leaching. For example McCracken et al. (1989) used standard statistical analysis to show that measurements of surface soil $\mathrm{NO}_{3}-\mathrm{N}$ reflected the past management practices at the scale of experimental plots. The interactions of water and nitrogen on crop biomass have also been studied for many crops (Vázquez et al., 2006, and references there in). The practice of drip fertigation has the potential to increase water and nitrogen use efficiency (Castellanos et al., 2010). However, a disadvantage associated with it is that the nitrogen travels outside of the root zone (Thompson and Doerge, 1996). Accumulation and redistribution of nitrogen within the soil varies depending on

Published by Copernicus Publications on behalf of the European Geosciences Union. 
management practices, soil characteristics and precipitation, and these effects are likely to contribute to variation at different spatial frequencies. None of the studies of which we are aware consider the effect of previous treatments over a range of spatial frequencies; and, given the particular processes associated with fertigation, we wished to do so in this study.

The data discussed in this paper result from two consecutive experiments done near the Mancha Occidental aquifer (U.H.04.04, $6953 \mathrm{~km}^{2}$ ) and Campo de Montiel aquifer (U.H. $04.06,3192 \mathrm{~km}^{2}$ ). In the first experiment, which is reported in Castellanos et al. (2010), the effect of nine different fertigation treatments on melon yield were investigated. Each treatment had a different level of nitrogen, and so constituted a known contribution to the variation of soil nitrogen at predominantly low frequency. The melon crop removed a proportion of the nitrogen at a higher spatial frequency dictated by its cropping density. After the melons were harvested the second experiment was started. Wheat was sown across the plots. At harvest time a transect was selected that crossed nine former subplots each with a different treatment history. The wheat was harvested in consecutive sections along the transect and biomass measured. The wheat was effectively used as a nitrogen sink crop and allowed us to evaluate the soil nitrogen residual. From melon fertigation to wheat harvest, a set of processes influencing the nitrogen cycle has occurred: nitrogen uptake by the melon crop, organic soil nitrogen mineralization, nitrogen leaching, horizontal diffusion of soluble nitrogen forms and nitrogen uptake by the wheat crop. The aim of this study was to investigate the residual effects on wheat biomass of the fertigation treatments applied to the melon crop. We were interested in these effects at a range of spatial frequencies and not simply the plot scale because we expected different processes to dominate different spatial frequencies. For example, we hypothesized that residual effects from fertilizer application would dominate low spatial frequencies and that the local influence of individual plants from the previous melon crop would dominate high frequency. As noted above, understanding the frequencies at which processes dominate variation and quantifying their impact has relevance to precision agriculture. We chose to investigate the relationship between applied nitrogen, melon cropping and wheat biomass using the maximum overlap discrete wavelet packet transform (MODWPT) as this method is well suited for an analysis of the (co)variation of variables at different spatial frequencies when assumptions of uniformity (stationarity) are likely to not hold (see Percival and Walden, 2000).

The MODWPT, as the name suggests, is a development of the discrete wavelet transform. Wavelets were developed in the 1980s for signal processing, and later introduced to soil science by Lark and Webster (1999) as a method to evaluate soil variation in situations where the magnitude of variation changes between spatial scales and from place to place. Since then they have been applied in several pedological case studies which consider soil property variation and correlation between variables at different spatial scales (or frequencies) (Lark et al., 2004; Milne et al., 2005; Lark, 2006; Biswas et al., 2008). To our knowledge the MODWPT has not previously been used to identify and quantify the carry-over effects of previous treatments on crop biomass. The MODWPT decomposes a series (whether this be a time series, or as in our case a series of measurements made along a transect) into wavelet packet (WP) coefficients which describe local variation in the series at different frequency intervals, giving up some resolution in space. Wavelet packet coefficients can be used to estimate frequency-specific components of variation and correlation. The former allows us to see which frequencies contribute most to signal variation, and the latter enables us to estimate the correlation between two series across different frequency intervals. This can give us an insight into the dominant processes and how they may relate to a second known variable. In addition, because WP coefficients retain information on the position of features we are able to see if there are any significant changes in variation or correlation across the series, reflecting changes in the dominant process.

\section{Material and methods}

\subsection{Field experiment}

The field trials were carried out at La Entresierra field station located in Ciudad Real, central Spain $\left(3^{\circ} 56^{\prime} \mathrm{W} ; 39^{\circ} 0^{\prime} \mathrm{N}\right.$; $640 \mathrm{~m}$ altitude) from April 2006 to June 2007. The melon crop experiment is described more fully in Castellanos et al. (2010). The soil is classified as Alfisol Xeralf Petrocalcic in the USDA system (Soil Survey Staff, 1999). It overlays fragmented petrocalcic horizon and is shallow in depth, reaching a maximum of $60 \mathrm{~cm}$ with very little vertical variation. The soil is sandy-loam in texture, slightly basic $(7.9 \mathrm{pH})$, medium in organic matter $(2.2 \%)$, rich in potassium $(0.9-1.0 \mathrm{mEq}$ $(100 \mathrm{~g})^{-1}$, ammonium acetate $)$ and with a medium level of phosphorous (16.4 to $\left.19.4 \mathrm{mEq}(100 \mathrm{~g})^{-1}\right)$ with ECw. 0.1$0.2 \mathrm{dS} \mathrm{m}^{-1}$.

The area is characterized by a continental Mediterranean climate, with widely fluctuating daily temperatures. In the three years prior to this experiment, non-irrigated winter wheat (Triticum aestivum L.) was grown on the plots, to which no organic matter or fertilizers were added.

\subsubsection{Melon crop experiment}

The melon species used in the experiment was Piel de sapo (Cucumis melo L., var. inodorous, cv. Sancho). This is the most widely cultivated melon in Spain. Seeds were germinated in a greenhouse in April 2006. On 24 May 2006, when they had sprouted two or three real leaves, they were transplanted onto plastic mulch at a density of 4444 plants $\mathrm{ha}^{-1}$ (i.e. at $1.5 \mathrm{~m}$ spacings). A randomized split plot design was used, with three nitrogen levels and three irrigation 
Table 1. The treatments applied to the melon crop, reference evapotranspiration $E_{0}$ (15 to 104 DAT) and estimated crop evapotranspiration $E_{\mathrm{c}}$ values (15 to $104 \mathrm{DAT}$ ), total irrigation (applied irrigation, taking initial establishment irrigation into account, in the different treatments: $60 \% E_{\mathrm{c}}(\mathrm{W} 1), 100 \% E_{\mathrm{c}}(\mathrm{W} 2)$ and $\left.140 \% E_{\mathrm{c}}(\mathrm{W} 3)\right)$ and applied nitrogen information

\begin{tabular}{|c|c|c|c|c|c|c|c|c|}
\hline $\begin{array}{l}\text { Irrigation } \\
\text { treatment }\end{array}$ & $\begin{array}{l}\text { Fertilizer } \\
\text { treatment }\end{array}$ & $\begin{array}{c}E_{0} \\
(\mathrm{~mm})\end{array}$ & $\begin{array}{c}E_{\mathrm{c}} \\
(\mathrm{mm})\end{array}$ & $\begin{array}{l}\text { Total irrigation } \\
(\mathrm{mm})\end{array}$ & $\begin{array}{l}\text { Total rain } \\
(\mathrm{mm})\end{array}$ & $\begin{array}{c}\text { Total } N \text { in } \\
\text { irrigation water } \\
\left(\mathrm{kg} \mathrm{N} \mathrm{ha}^{-1}\right)\end{array}$ & $\begin{array}{c}\text { Total } N \text { in } \\
\text { fertilizer } \\
\left(\mathrm{kg} \mathrm{N} \mathrm{ha}^{-1}\right)\end{array}$ & $\begin{array}{c}\text { Total } \\
\text { applied } N \\
\left(\mathrm{~kg} \mathrm{~N} \mathrm{ha}^{-1}\right)\end{array}$ \\
\hline W1 & $\begin{array}{l}\text { N0 } \\
\text { N1 } \\
\text { N2 }\end{array}$ & 572.12 & 419.68 & 342.6 & 19.50 & 55.58 & $\begin{array}{c}0 \\
150 \\
300\end{array}$ & $\begin{array}{c}55.58 \\
205.58 \\
355.58\end{array}$ \\
\hline W2 & $\begin{array}{l}\text { N0 } \\
\text { N1 } \\
\text { N2 }\end{array}$ & 572.12 & 419.68 & 552.9 & 19.50 & 92.78 & $\begin{array}{c}0 \\
150 \\
300\end{array}$ & $\begin{array}{c}92.78 \\
242.78 \\
392.78\end{array}$ \\
\hline W3 & $\begin{array}{l}\mathrm{N} 0 \\
\mathrm{~N} 1 \\
\mathrm{~N} 2\end{array}$ & 572.12 & 419.68 & 755.9 & 19.50 & 129.46 & $\begin{array}{c}0 \\
150 \\
300\end{array}$ & $\begin{array}{l}129.46 \\
279.46 \\
429.46\end{array}$ \\
\hline
\end{tabular}

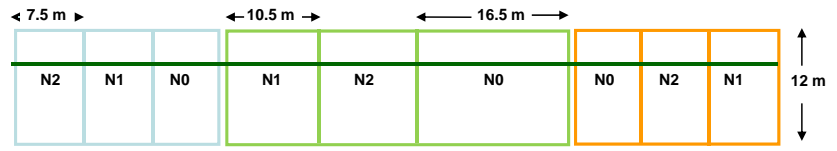

Legend $\square$ W1 $(60 \% \mathrm{Ec}), \square$ W2 $(100 \% \mathrm{Ec}), \square$ W3 $(140 \% \mathrm{Ec}), \quad-\quad$ Transect

Fig. 1. An illustration of the experimental layout. Only the nine subplots of the melon crop experiment through which the wheat transect ran are shown. The wheat transect is shown by the dark green line. The fertilizer levels are shown on the figure: N0, N1, N2 represent 0,150 and $300 \mathrm{~kg} \mathrm{~N}^{-1}$ respectively. The three different irrigation levels are indicated by the colour of the subplot lines: light blue is $\mathrm{W} 1$, the light green $\mathrm{W} 2$, and the orange W3 corresponding to $60 \%, 100 \%$, and $140 \%$ of the estimated crop evapotranspiration $\left(E_{\mathrm{c}}\right)$ respectively.

levels. The irrigation treatment was applied at the main plot level and nitrogen-rates replicated in subplots. Each treatment was replicated four times in subplots measuring between $7.5-16.5 \mathrm{~m}$ in width and $12 \mathrm{~m}$ in length. The subplot widths ranged in size for practical reasons. The plots were arranged on a four by nine grid (the part of the grid relevant to this study is shown in Fig. 1). Each subplot had five, seven or eleven rows of melons, according to its width (melon rows run from top to bottom in Fig. 1).

Each row of melons was drip irrigated, at a rate of $21 \mathrm{~h}^{-1}$, from a line with emitters spaced at $0.5 \mathrm{~m}$. In order to facilitate the crop establishment, all plots received $30 \mathrm{~mm}$ of water immediately after they were transplanted. Following this the irrigation schedule for each treatment was calculated daily. There was no irrigation for the first 14 day. Then every day, for the next 90 days, a single irrigation of $60 \%$ (W1), $100 \%$ (W2) or $140 \%$ (W3) of the melon crop evapotranspiration
$\left(E_{\mathrm{c}}\right)$ value was applied - see Table 1. Each day crop evapotranspiration $\left(E_{\mathrm{c}}\right)$ was calculated following the FAO method (Doorenbos and Pruitt, 1977) given by

$E_{\mathrm{c}}=K_{\mathrm{c}} E_{0}$

where $K_{\mathrm{c}}$ is the crop coefficient, that was obtained for melon crops previously grown in the same area (Ribas et al., 1995) and $E_{0}$ is the reference evapotranspiration calculated using the FAO Penman-Monteith method (Allen et al., 2002). The total irrigation applied was $342.6,552.9$ and $755.9 \mathrm{~mm}$ for $\mathrm{W} 1, \mathrm{~W} 2$ and $\mathrm{W} 3$ respectively. The irrigation water quality was measured weekly to estimate the nitrogen content of the water. The three fertilizer treatment levels include nitrogen, in the form of ammonium nitrate, at doses 0,150 and $300 \mathrm{~kg}$ $\mathrm{N} \mathrm{ha}^{-1}$. We denote these levels N0, N1 and N2 respectively. The fertilizer was applied throughout a 10 week period starting in June by mixing it with the irrigation water. As the irrigation water carried some nitrogen, all the treatments add nitrogen to the soil. The total nitrogen applied is shown in Table 1.

The plots were also fertilized with a total of $120 \mathrm{~kg} \mathrm{ha}^{-1}$ of phosphoric acid over the season. This was added to the irrigation water daily, from three weeks after transplanting until the last week of August. Potassium was not applied due to the large content of this element in the soil. A standard disease- and insect-control programme was implemented throughout the growing period in accordance with usual management practice to ensure that the response to nitrogen fertilizers would not be masked by other factors. Melons were harvested when there was a significant amount of ripe fruit in the field from 26 July to 7 September with a total of seven harvests. 
A. E. Milne et al.: Using the MODWPT to expose the relationship between wheat biomass and past treatments

\begin{tabular}{|c|c|c|c|c|c|c|c|c|c|c|c|c|c|c|c|}
\hline \multicolumn{16}{|c|}{$z(x)$} \\
\hline \multicolumn{8}{|c|}{$\mathrm{u}_{1,1}$} & \multicolumn{8}{|c|}{$\mathrm{u}_{1,2}$} \\
\hline \multicolumn{4}{|c|}{$\mathrm{u}_{2,1}$} & \multicolumn{4}{|c|}{$\mathrm{u}_{2,2}$} & \multicolumn{4}{|c|}{$\mathrm{u}_{2,3}$} & \multicolumn{4}{|c|}{$\mathrm{u}_{2,4}$} \\
\hline \multicolumn{2}{|c|}{$\mathrm{u}_{3,1}$} & \multicolumn{2}{|c|}{$\mathrm{u}_{3,2}$} & \multicolumn{2}{|c|}{$\mathrm{u}_{3,3}$} & \multicolumn{2}{|c|}{$\mathrm{u}_{3,4}$} & \multicolumn{2}{|c|}{$u_{3,5}$} & \multicolumn{2}{|c|}{$u_{3,6}$} & \multicolumn{2}{|c|}{$\mathrm{u}_{3,7}$} & \multicolumn{2}{|c|}{$u_{3,8}$} \\
\hline $\mathrm{u}_{4,1}$ & $\mathrm{u}_{4,2}$ & $\mathrm{u}_{4,3}$ & $\mathrm{u}_{4,4}$ & $\mathrm{u}_{4,5}$ & $\mathrm{u}_{4,6}$ & $\mathrm{u}_{4,7}$ & $\mathrm{u}_{4,8}$ & $\mathrm{u}_{4,9}$ & $\mathrm{u}_{4,10}$ & $\mathrm{u}_{4,11}$ & $\mathrm{u}_{4,12}$ & $\mathrm{u}_{4,13}$ & $\mathrm{u}_{4,14}$ & $\mathrm{u}_{4,15}$ & $\mathrm{u}_{4,16}$ \\
\hline & & & & & & & & & & & & & & & \\
\hline & & & & $/ 8 x_{0}$ & & & Fre & $\begin{array}{l}/ 4 x_{0} \\
\text { ency }\end{array}$ & & & & & & & \\
\hline
\end{tabular}

Fig. 2. The MODWPT decomposition of a series $z(x)$, where $x=1,2, \ldots, N$ up to level $j=4$. The nominal frequency ranges associated with each WP filter $u_{\mathrm{j}, \mathrm{m}}$ are shown. The darker shaded wavelet packets are an example of a complete basis.

\subsubsection{Wheat crop experiment}

Winter wheat (Triticum aestivum L., cv. Soissons) was grown on the same experimental site as the melon crop discussed above. It was sown on 20 December 2006 in rows spaced $0.15 \mathrm{~m}$ apart at a density of 400 seeds $\mathrm{m}^{-2}$. Post-emergence herbicides were used to control weeds. No fertilizer or organic amendments were applied during the season, so this was in effect a uniform trial. A transect was selected running perpendicular to the irrigation lines, which went through nine treatment plots (see Fig. 1). On 6 June 2007 the wheat crop was harvested. Each $0.5 \mathrm{~m}$ a frame of $0.5 \mathrm{~m} \times 0.5 \mathrm{~m}$ was placed on the soil and the wheat plants captured were harvested and placed in labeled bags.

For each sample, wheat grain was separated from the rest of the plant so that we could measure both grain dry-weight and plant biomass. These were determined by oven drying at $80^{\circ} \mathrm{C}$ to a constant weight. We chose to investigate the frequency-dependent relationship between applied nitrogen, melon position and wheat biomass in this study, but we could have equally well chosen to look at grain weight. The two are strongly correlated $\left(R^{2}>0.96\right)$ so this would have made little difference to our conclusions.

\subsection{The wavelet packet transform}

There are many good explanations of the MODWPT, most notably Percival and Walden (2000). Therefore we only give a brief description.

If we consider a series of $N$ observations $z(x), x=1, \ldots, N$ made at regularly spaced intervals of $x_{0}$. The MODWPT is achieved by convolving the original series $z(x)$, with a subset of the WP filters $\boldsymbol{u}_{\mathrm{j}, \mathrm{m}}$ where $m=1, \ldots, 2^{j}$ and $j=1, \ldots, J$ where $J$ is a positive integer such that $2^{J} \leq N$. The filter $\boldsymbol{u}_{\mathrm{j}, \mathrm{m}}$ retains information on the series from the frequency interval $\left[\frac{m-1}{2^{j+1} x_{0}}, \frac{m}{2^{j+1} x_{0}}\right]$, although there is some leakage. It follows that the filters $\boldsymbol{u}_{\mathrm{j}, \mathrm{m}}$ where $m=1, \ldots, 2^{j}$ decompose the frequency interval $\left[0, \frac{1}{2 x_{0}}\right]$ into $2^{j}$ equal intervals, as illustrated in Fig. 2. We call these frequency intervals wavelet packets. Any set of WPs with non-overlapping frequency intervals, which cover the whole frequency interval form a complete WP basis which we can use to decompose the original series. An example of a complete WP basis is illustrated in Fig. 2 by the darker shading.
Each filter $\boldsymbol{u}_{\mathrm{j}, \mathrm{m}}$ is non-zero for only a small interval length $L_{\mathrm{j}}$ (i.e. $\left.\boldsymbol{u}_{\mathrm{j}, \mathrm{m}}=\left\{u_{\mathrm{j}, \mathrm{m}}(l): l=1, \ldots, L_{\mathrm{j}}\right\}\right)$, and so when convolved with the original series $z(x)$ results in $N$ WP coefficients given by

$w_{\mathrm{j}, \mathrm{m}}(x)=\sum_{i=1}^{L_{\mathrm{j}}} u_{\mathrm{j}, \mathrm{m}}(i) z(x-i)$ for $x=1, \ldots, N$.

For this application we padded the series by reflection where the filter overlapped the ends. The wavelet coefficient $w_{\mathrm{j}, \mathrm{m}}(x)$ can be thought of as a measure of how similar the original series is to the filter $\boldsymbol{u}_{\mathrm{j}, \mathrm{m}}$ located at position $x$. In other words, each wavelet coefficient $w_{\mathrm{j}, \mathrm{m}}(x)$ captures a component of variation local to the nominal position $x$ of the coefficient, and is associated with frequency interval $\left[\frac{m-1}{2^{j+1} x_{0}}, \frac{m}{2^{j+1} x_{0}}\right]$.

Percival and Walden (2000) describe how each filter is computed from a mother wavelet filter $\left\{h_{0}(l): l=1, \ldots, L\right\}$ and associated father wavelet filter $\left\{g_{0}(l): l=1, \ldots, L\right\}$, where $h_{0}(l)=(-1)^{l-1} g_{0}(L-1-l)$. In our analysis we used Daubechies's extremal phase wavelet filter with two vanishing moments (Daubechies, 1992). We selected this wavelet because it has a very compact support (i.e. it takes non-zero values over a narrow interval, $L=4$, and so is particularly suitable for identifying localized features in the data).

We see from Fig. 2 that with increasing level number $j$ we obtain increased frequency resolution. This is at the expense of resolution in space because the filter length increases with level number, and so the associated wavelet coefficients result from a weighted sum of a larger portion of the original series. The MODWPT basis is generally selected to suit the data by trading resolution in space for resolution in the frequency domain. Usually it is desirable to select a basis that concentrates variance in as few wavelet coefficients as possible (Percival and Walden, 2000; Lark, 2006). This results in good frequency resolution over stationary stretches and good spatial resolution at frequencies with short-range episodic noise. In practice we identify the "best" basis $\Omega_{B}$ by minimizing a suitable cost function $\Omega\left(w_{\mathrm{j}, \mathrm{m}}\right)$, here we use the cost function proposed by Constantine and Reinhall (2001), that is:

$\Omega_{B}=\min _{\Phi} \sum_{(\mathrm{j}, \mathrm{m}) \in \Phi} \Omega\left(w_{\mathrm{j}, \mathrm{m}}\right)$

where 
$\Omega\left(w_{\mathrm{j}, \mathrm{m}}\right)=$

$-2^{-j} \sum_{x=1}^{N}\left(\frac{2^{-j / 2} w_{\mathrm{j}, \mathrm{m}}(x)}{\|z\|}\right)^{2} \ln \left(\frac{2^{-j / 2} w_{\mathrm{j}, \mathrm{m}}(x)}{\|z\|}\right)^{2}$

where $\Phi$ is the space spanned by all sets of packets with nonoverlapping frequency intervals, which cover the whole frequency interval, and $\|z\|$ is the norm of $z(x), x=1, \ldots, N$.

\subsubsection{Multiresolution analysis}

The MODWPT is invertible which means we can recover the original series from the WP coefficients. A more useful consequence of this is that if we set all coefficients to zero, with the exception of those associated with a given frequency interval (for example $\left\{w_{\mathrm{j}, \mathrm{m}}(x): x=1, \ldots, N\right\}$ ) and then do the reconstruction we obtain the component of the original signal corresponding to that frequency interval. Breaking the signal down into frequency specific components (known as muliresolution analysis) enables us to visualize the components of variation for each frequency interval. This is often difficult to do from visual inspection of the original series.

\subsubsection{The wavelet packet variance and correlation}

MODWPT coefficients can be used to estimate the partition of variance between WPs. The variance associated with a particular WP is known as the sample WP variance, and is estimated by

$\sigma_{\mathrm{j}, \mathrm{m}}^{2}=\frac{1}{\hat{N}_{j}} \sum_{x=a}^{b} w_{\mathrm{j}, \mathrm{m}}(x)^{2}$

where $\hat{N}_{j}=b-a+1$, typically $a=L_{j}$ and $b=N$ (Percival and Walden, 2000). For short series, such as the one discussed here, these limits can mean that for frequency intervals of interest we discard a large proportion of the WP coefficients in our estimation of WP variance. Therefore we use values of $a$ and $b$ derived by the method described in Milne et al. (2009). Similarly the WP coefficients can be used to estimate WP covariance $C_{\mathrm{j}, \mathrm{m}}$ between two variables $z(x)$ and $v(x)$. This is given by

$C_{j, m}=\frac{1}{\hat{N}_{j}} \sum_{x=a}^{b} w_{\mathrm{j}, \mathrm{m}, \mathrm{z}}(x) w_{\mathrm{j}, \mathrm{m}, \mathrm{v}}(x)$

where $w_{\mathrm{j}, \mathrm{m}, \mathrm{z}}(x)$ and $w_{\mathrm{j}, \mathrm{m}, \mathrm{v}}(x)$ are the WP coefficients of variables $z(x)$ and $v(x)$ respectively. It follows that the WP correlation $\rho_{\mathrm{j}, \mathrm{m}}$ is given by

$\rho_{\mathrm{j}, \mathrm{m}}=\frac{C_{\mathrm{j}, \mathrm{m}}}{\sqrt{\sigma_{\mathrm{j}, \mathrm{m}, \mathrm{z}}^{2} \sigma_{\mathrm{j}, \mathrm{m}, \mathrm{v}}^{2}}}$

(see Percival and Walden, 2000 and Milne et al., 2009).
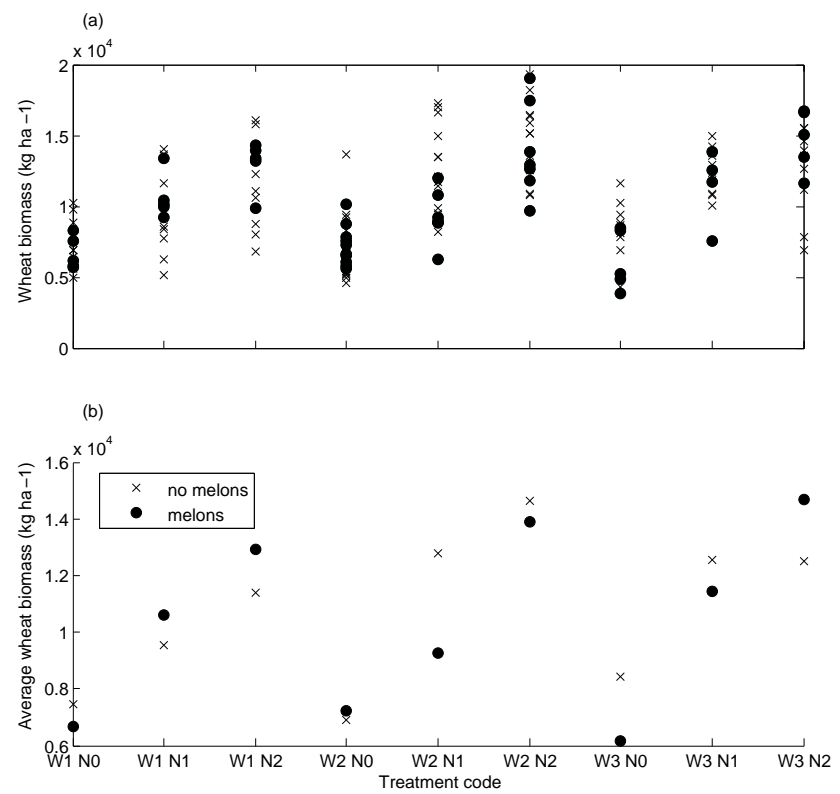

Fig. 3. (a) Wheat biomass $\left(\mathrm{kg} \mathrm{ha}^{-1}\right)$ from locations where melons once grew $(\bullet)$ and where they did not $(\times)$ plotted against fertigation treatment type, and (b) the mean for each treatment plotted against treatment type. Treatment types were as follows. Total irrigation levels of 342.6, 552.9 and $755.9 \mathrm{~mm}$ are denoted $\mathrm{W} 1, \mathrm{~W} 2$, and W3 respectively. Fertilizer treatments of 0,150 and $300 \mathrm{~kg} \mathrm{ha}^{-1}$ are denoted N0, N1 and N2 respectively.

As we explained above, the WP coefficients capture local components of variance at specific frequency intervals, and so we can see also how WP variation changes with location. Milne et al. (2009) describe a method of detecting changes in WP variance at a given frequency, based on a proposal by Whitcher et al. (2000), and testing to see if the changes are significant based on a null hypothesis that the data are a realization of a random variable that is stationary in the variance. A similar method can be used to detect significant changes in WP correlation (see Milne et al., 2009).

The MODWPT results are typically discussed in terms of frequency, but sometimes period (the reciprocal of frequency) is a more intuitive way to present results. In the following we use both concepts. As observations were made every $0.5 \mathrm{~m}$ the conversion from frequency $f$ (cycles observation $\left.^{-1}\right)$ to period $p(\mathrm{~m})$ is given by $p=(2 f)^{-1}$.

\section{Results and discussion}

\subsection{Exploratory analysis}

Figure 3a shows the wheat biomass for each of the 18 treatment types (fertilizer level $\times$ irrigation level $\times$ melon occurrence). The mean for each treatment is plotted in Fig. 3b. From the plots we see that the average wheat biomass increases with increasing fertilizer application. 

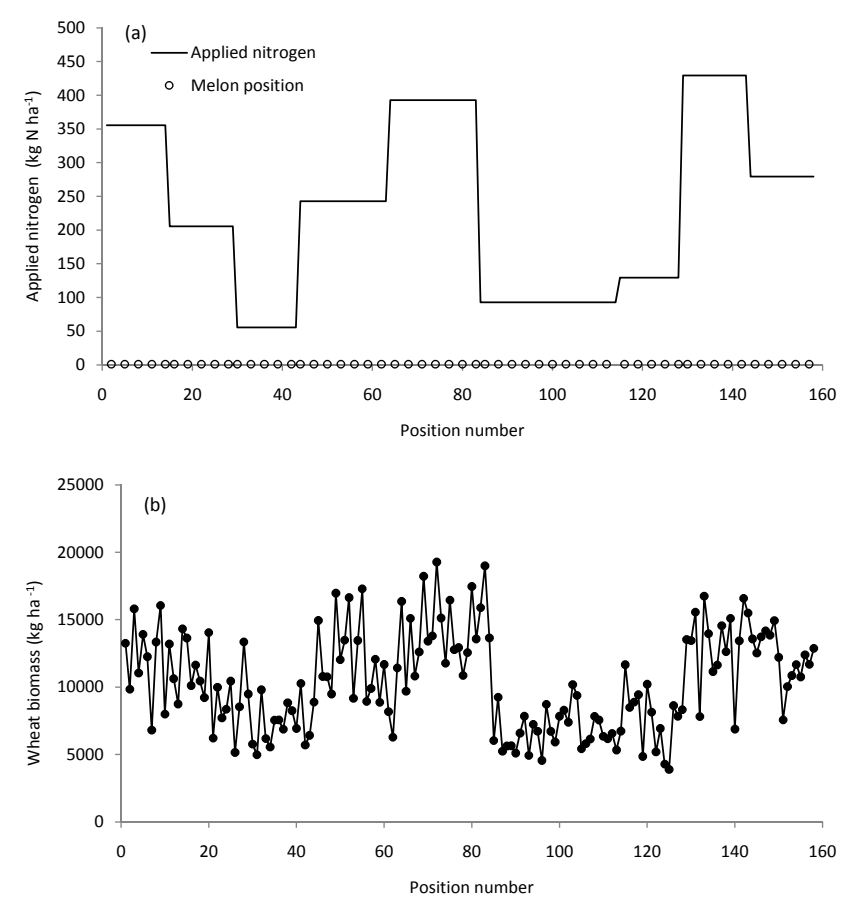

Fig. 4. (a) Applied nitrogen $\left(\mathrm{kg} \mathrm{N} \mathrm{ha}^{-1}\right)$ plotted against position. The location of the melon rows are shown by the symbol o. (b) The wheat biomass $\left(\mathrm{kg} \mathrm{ha}^{-1}\right)$ plotted against position.

Wavelet analysis requires a series of equally spaced values. Measurements of wheat biomass were made every $0.5 \mathrm{~m}$. A series describing melon plant position at this frequency was constructed by assigning 1 to locations with melons and 0 where there were none. The position of the transect relative to the fertigation lines (i.e. perpendicular) meant that fertigation occurs at intervals of approximately $1.5 \mathrm{~m}$ along the transect, coincidental with the melon plants. However, because the nitrogen and water are assumed to be easily transported from the sources we assume nitrogen was applied evenly across each plot. Figure 4a shows the applied nitrogen and melon position across the transect and Fig. $4 \mathrm{~b}$ shows the wheat biomass along the transect.

\subsection{The best basis}

We calculated the "best basis" for wheat biomass (our variable of central interest), and then used this WP basis in the remainder of the analysis. The best basis is illustrated in Fig. 5 . This basis generally favours frequency resolution over spatial resolution, as predominantly the packets are from level 5 and 4. Only the highest frequency packet is not.

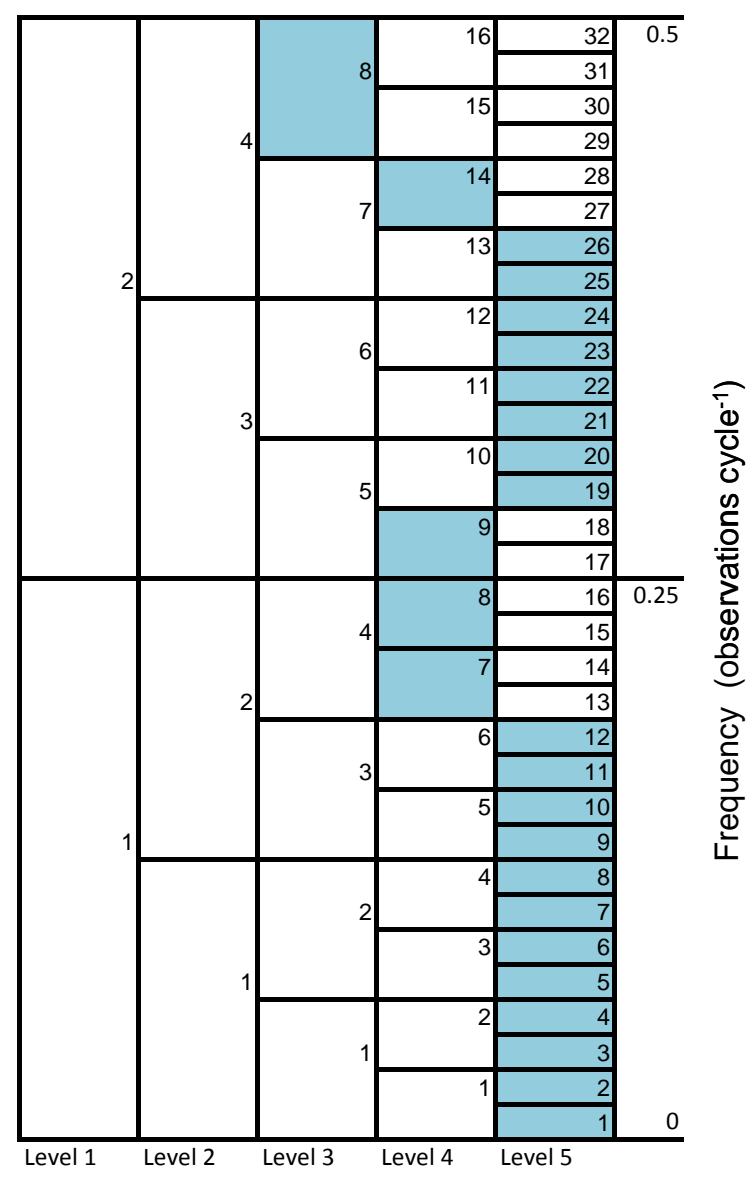

Fig. 5. The "best bases" for wheat biomass. The nominal partition of the frequency interval by the MODWPT to level 5 is shown with the best bases indicated by the shading. Packet associated with filter $\boldsymbol{u}_{\mathrm{k}, \mathrm{m}}$ is identified by level number $k$ on the bottom of the grid, and packet number $m$ in the cell.

\subsection{Multiresolution analysis}

Figure 6 shows the MRA of wheat biomass. The components are stacked one upon another from the highest frequency components at the bottom to the lowest at the top. We see that the low frequency reflects the applied nitrogen closely (see Fig. 4a) as do the next two lowest frequency MRA components.

\subsection{Wavelet packet variance}

The WP variance was estimated for each variable. Figure 7 shows the results. As the frequency interval changes from packet to packet, depending on which level of decomposition it came from, a simple graph of WP variance against frequency can mislead. Therefore we have plotted the WP variance divided by the associated frequency interval against the midpoint of the frequency interval. This quantity is a standardized WP variance for the frequency interval. The 


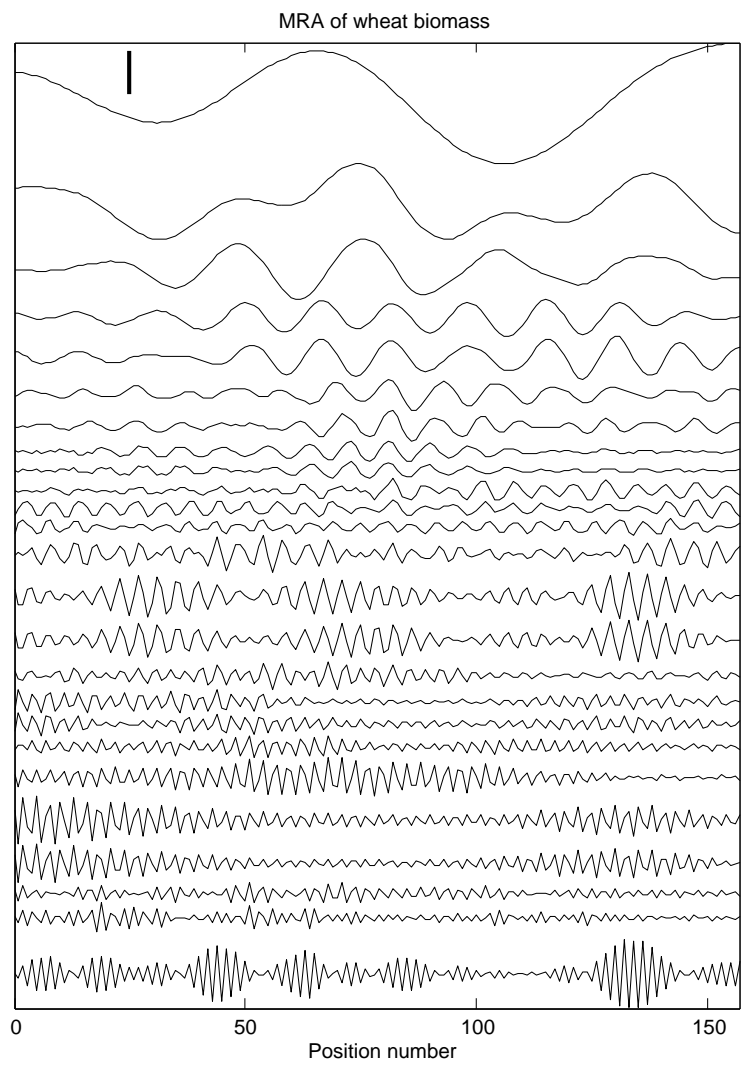

Fig. 6. Multiresolution analyses of wheat biomass decomposed on the "best basis". The components are stacked from highest frequency at the bottom to lowest frequency at the top (residual once other components are removed). The scale-bar is shown by the vertical bar on the plot and this is of length $50 \mathrm{~kg} \mathrm{ha}^{-1}$.

95\% confidence interval for each estimate is also shown. For some estimates (which are associated with packets from level 5) there are large confidence intervals. This is because the effective degrees of freedom for these estimates is very low, which is a consequence of the length of the filters from level $5\left(L_{5}=94\right)$ and the data numbering only 158 (see Milne et al., 2009; Lark and Webster, 2001).

The largest contribution to WP variance for applied nitrogen is at the lowest frequency interval. After the first three packets WP variation is relatively small. Not surprisingly these first three packets correspond to frequencies between 0.0156-0.0625 cycles per observation, which corresponds to an interval of periods of $8-32 \mathrm{~m}$. The narrowest subplot width is $7.5 \mathrm{~m}$, so the first three packets correspond to subplot scale variation. The dominant frequencies for melon position WP variation are $0.33-0.36$ cycles per observation (interval of periods $1.4-1.5 \mathrm{~m}$, which is the approximate spacing between melon plants), the peak at $0.14-0.19$ is likely to be a harmonic of this. Interestingly, the largest contributions to WP variance of applied nitrogen and melon position are reflected in the wheat biomass results. We see that the largest
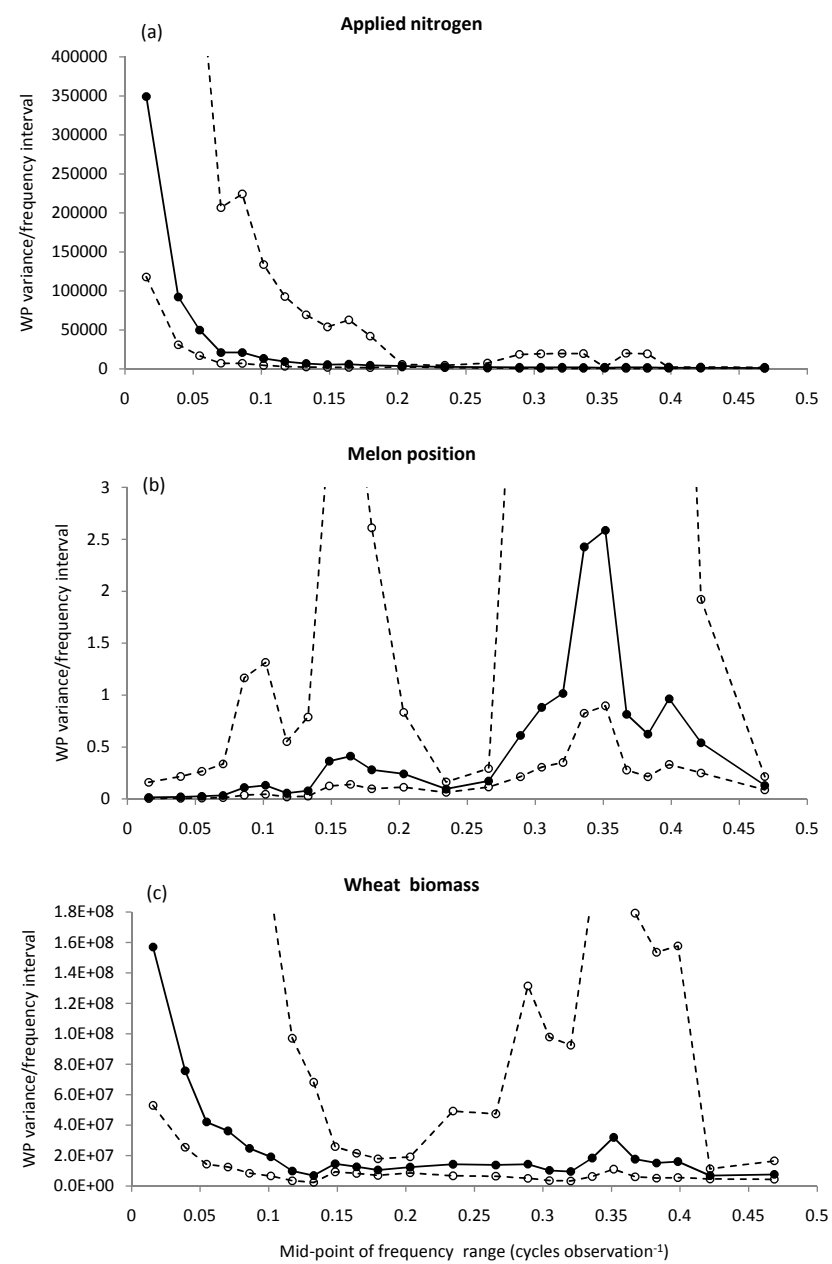

Fig. 7. The solid symbols show the standardized WP variances for (a) applied nitrogen, (b) melon position and (c) wheat biomass plotted against the mid-point of the corresponding frequency interval. The $95 \%$ confidence interval for each estimate are shown by the open symbols. The solid and dotted lines that join the symbols are to aid visual interpretation.

peak in WP variation, like the applied nitrogen WP variance, is at the lowest frequency. This suggests, perhaps not surprisingly, that in this experiment the applied nitrogen is the main reason for the observed variation in wheat biomass. There is a smaller but noticeable peak in variation at the 0.34-0.36 frequency interval consistent with the largest WP variance contribution of melon position. This suggests melon position is having a small but noticeable effect on wheat biomass variation.

\subsection{Wavelet packet correlation}

The WP correlations between applied nitrogen and wheat biomass (Fig. 8) show that at low frequencies the variables have large correlations $(>0.91)$ which are significantly different from zero (based on the 95\% confidence interval). 

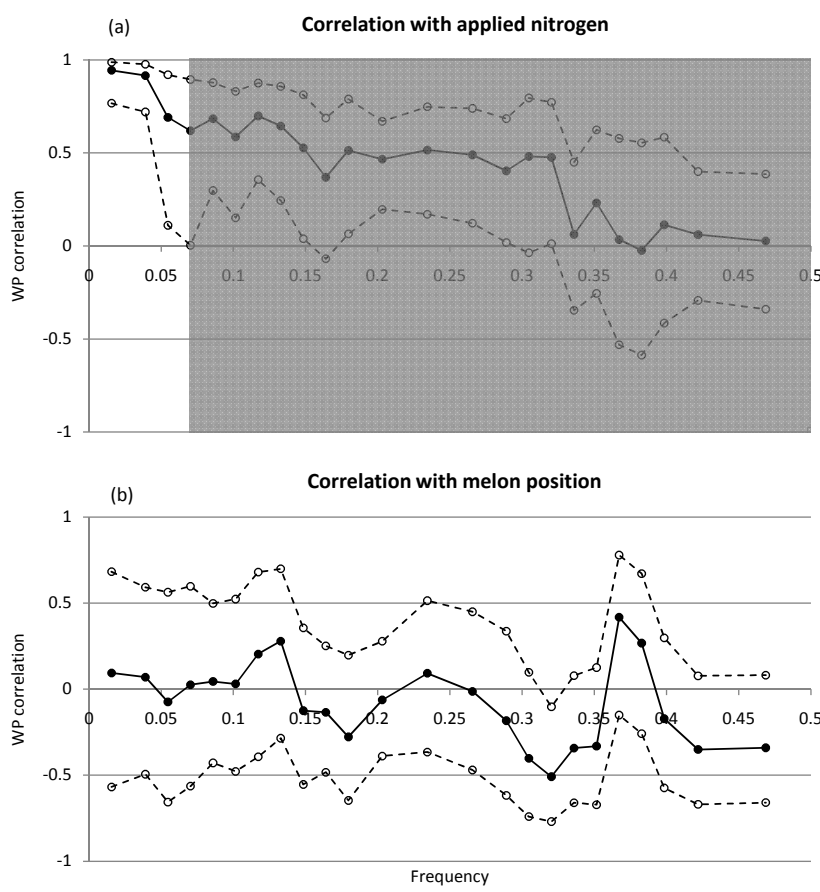

Fig. 8. The solid symbols show the wavelet packet correlations between (a) applied nitrogen and wheat biomass, and (b) melon position and wheat biomass plotted against the mid-point of the corresponding frequency interval. The $95 \%$ confidence interval for each estimate are shown by the open symbols. The solid and dotted lines that join the symbols are to aid visual interpretation. In Figure (a) the WP correlations at frequencies larger than 0.0625 are greyed out because there is negligible variation in applied nitrogen at these higher frequency packets (as can be seen in Fig. 7).

Although not strictly equivalent, this quantifies the observations made above on the MRA. As frequency increases, the correlation becomes weaker and not significantly different from zero. At these higher frequencies there is very little WP variation in applied nitrogen. The little high frequency WP variation present is an artefact resulting from the assumed step change in applied nitrogen between plots. The WP correlation at these high frequencies measures to what degree the artifacts propagated by the edge effects appear in the wheat biomass. We found only one significant change in correlation between these two variables. This was in packet 18 at location 26 where correlation went from weakly negative and not significantly different from zero, to 0.48 and significantly different from zero.

Assuming that the melon crop depletes the nitrogen locally, we would expect to see negative correlations between melon position and wheat biomass at certain scales. The only correlation that is significantly different from zero is negative $(-0.5)$ and is associated with frequency interval 0.31-0.33, i.e. slightly lower than the frequency interval associated with the largest WP variation of melon position (0.33-0.36 cycles per observation). The WP correlations at these intervals are negative but weak $(-0.34)$ and not significantly different from zero. There is a significant change in WP correlation in packet 19 (frequency interval $0.33-0.34$ cycles per observation) at location 91 . The correlation goes from -0.53 and significantly different from zero to weak positive not significantly different from zero. This means that between locations 1-91 the observed behaviour is consistent with what we expect, and there after it is not (there is another significant change in correlation in packet 17 but neither correlation is significantly different from zero or shed light on the process).

\section{Conclusions}

In this study we investigated the residual effects on wheat biomass of fertigation treatments applied to a previous crop. Our aim was not simply to detect them but to quantify their effect on the wheat biomass at a full range of spatial frequencies. This was because we wanted to identify the dominant processes operating at different frequencies so that we could estimate how much of the variation in wheat biomass could be attributed to both fertigation and nitrogen up-take by the melon plants. This sort of information is of potential relevance to precision farming since the decisions on spatially variable nitrogen rates may need to take account of previous variable inputs. The MODWPT is well suited for this kind of problem; and to our knowledge, this is the first time that it has been used to investigate residual effects of treatments on soil properties.

The WP correlation results show that at low frequencies there was a strong relationship between wheat biomass and applied nitrogen. At higher frequencies there was negligible variation in applied nitrogen. This is a consequence of the large spatial scale $(>7.5 \mathrm{~m})$ at which the treatments were applied, higher frequency variation is an artefact resulting from the assumed step change between treatments. The correlation between wheat biomass and applied nitrogen at high frequencies was weak. We might expect melon position to affect wheat biomass negatively, particularly where nitrogen is limiting and residual nitrogen is significant. This is because the melon crop will remove nitrogen from the soil reducing that available to the wheat crop. A simple inspection of the raw data shows that the relationship between the two is not that straightforward.

The WP correlations between melon position and wheat biomass also suggest little or no relationship between the two variables as they are generally weak and not significantly different from zero. However, interestingly there are coincidental peaks in variation at the $0.33-0.36$ frequency interval (interval of periods $1.4-1.5 \mathrm{~m}$ ). This means that there is a source of variation in wheat biomass that operates at the same frequency as the dominant frequency of variation in melon positioning. We can identify two possible causes (i) melon position does affect wheat biomass, but that other sources of 
variation mask the relationship, (ii) the fertigation does not diffuse uniformly across each area and so there is more nitrogen available to the wheat crop at locations where melons once grew. In fact it is likely to be a combination of the two which both operate at the same scale but will have opposite effects on wheat biomass.

The evidence shows that by far the greatest component of wheat-biomass variation resulted from the different rates of applied nitrogen. There is a small but notable component of variation at the scale associated with melon plant position, but in practical terms, the analysis showed there was no evidence that we should locally amend nitrogen following the melon crop either to account for nitrogen uptake by the melon or the nitrogen not diffusing uniformly across the plot. There was no evidence of other significant effects on biomass at the range of frequencies considered.

Acknowledgements. This project has been supported by INIARTA04-111. The wavelet analysis was done under Rothamsted Research's programme in Computational and Mathematical Biology, which is funded by the Biotechnology and Biological Sciences Research Council (BBSRC). A. M. Tarquis visited Rothamsted Research thanks to MEC under project PR2008-0091.

Edited by: W. Otten

\section{References}

Allen, R. G., Pereira, L. S., Raes, D., and Smith, M.: Crop evapotranspiration, Guidelines for computing crop water requirements, FAO irrigation and drainage paper 56, 3rd edition, 2002.

Bausch, W. C.: Impact of residual soil nitrate on in-season nitrogen applications to irrigated corn based on remotely sensed assessments of crop nitrogen status, Precis. Agric., 6, 509-519, 2005.

Biswas, A., Si, B. C., and Walley, F. L.: Spatial relationship between $\delta^{15} \mathrm{~N}$ and elevation in agricultural landscapes, Nonlin. Processes Geophys., 15, 397-407, doi:10.5194/npg-15-3972008, 2008.

Castellanos, M. T., Cartagena, M. C., Arce, A., Ribas, F., Cabello, M. J., and Tarquis, A. M.: Efficiency Indexes for melon crop optimization, Agron. J., 102, 716-722, 2010.

Constantine, W. L. B. and Reinhall, P. G.: Wavelet-based inband denoising technique for chaotic sequences, Int. J. Bifurcat. Chaos., 11, 483-495, 2001.

Daubechies I: Ten lectures on Wavelets, Society for Industrial and Applied Mathematics (SIAM), Philadelphia, 1992.

Doorenbos, J. and Pruitt, W. O.: Las necesidades de agua de los cultivos, Estudios F.A.O. Riego y Drenaje, 24. Ed FAO (Roma), 194, 1977.

Karlen, D. L., Kramer L. A., and Logsdon, S. D.: Field-scale nitrogen balances associated with long-term continuous continuous corn production, Agron. J., 90, 644-650, 1998.
Lark, R. M.: The representation of complex soil variation on wavelet packet bases, Eur. J. Soil Sci., 57, 868-882, 2006.

Lark, R. M., Milne, A. E., Addiscott, T. M., Goulding, K. W. T., Webster, C. P., and O'Flaherty, S.: Scale- and location-dependent correlation of nitrous oxide emissions with soil properties: an analysis using wavelets, Eur. J. Soil Sci., 55, 601-610, 2004.

Lark, R. M. and Webster, R.: Analysis and elucidation of soil variation using wavelets, Eur. J. Soil Sci., 50, 185-206, 1999.

Lark, R. M. and Webster, R.: Changes in variance and correlation of soil properties with scale and location: analysis using an adapted maximal overlap discrete wavelet transform, Eur. J. Soil Sci., 52, 547-5626, 2001.

McCracken, D. V., Corak, S. J., Smith, M. S., Frye, W. W., and Blevins, R. L.: Residual effects of nitrogen fertilization and winter cover cropping on nitrogen availability, Soil Sci. Soc. Am. J., 53, 1459-1464, 1989.

Milne, A. E., Lark, R. M., Addiscott, T. M., Goulding, K. W. T., Webster, C. P., and O'Flaherty, S.: Wavelet analysis of the scaleand location-dependent correlation of modelled and measured nitrous oxide emissions from soil, Eur. J. Soil Sci., 56, 3-17, 2005.

Milne, A. E., Macleod, C. J. A., Haygarth, P. M., Hawkins, J. M. B., and Lark, R. M.: The Wavelet Packet transform: a technique for investigating temporal variation of river water solutes, J. Hydrol., 379, 1-19, 2009.

Percival, D. B. and Walden, A. T.: Wavelet Methods for Time Series Analysis, Cambridge University Press, Cambridge, UK, 2000.

Ribas, F., Cabello, M. J., and Moreno, M. M.: Necesidades de riego del melón y respuesta del cultivo a riegos diferenciales en la provincia de Ciudad Real (Castilla-La Mancha), XIII Jornadas Tecnicas sobre Riegos, (Tenerife), 12-20, 1995.

Ruffo, M. L., Bullock, D. G., and Bollero, G. A.: Soybean yield as affected by biomass and nitrogen uptake of cereal rye in winter cover crop rotations, Agron. J., 96, 800-805, 2004.

Soil Survey Staff: Soil Taxonomy, A Basic System of Soil Classification for Making and Interpreting Soil Surveys, 2nd ed. United States Department of Agriculture, Natural Resources Conservation Service, Agric. Handbook No. 436, US Govt. Printing Office, Washington, DC, 20402, 869 pp., 1999.

Thompson, T. L. and Doerge, T. A.: Nitrogen and water interactions in subsurface trickle-irrigated leaf lettuce, II. Agronomic, economic, and environmental outcomes, Soil Sci. Soc. Am. J., 64, 412-418, 1996.

Vázquez, N., Pardo, A., Suso, M. L., and Quemada, M.: Drainage and nitrate leaching under processing tomato growth with drip irrigation and plastic mulching, Agr. Ecosyst. Environ., 112(4), 313-323, 2006.

Whitcher, B. J., Guttorp, P., and Percival, D. B.: Multiscale detection and location of multiple variance changes in the presence of long memory, J. Stat. Comput. Simul., 68, 65-88, 2000. 